\title{
Gene drives as a new quality in GMO releases - a comparative technology characterization
}

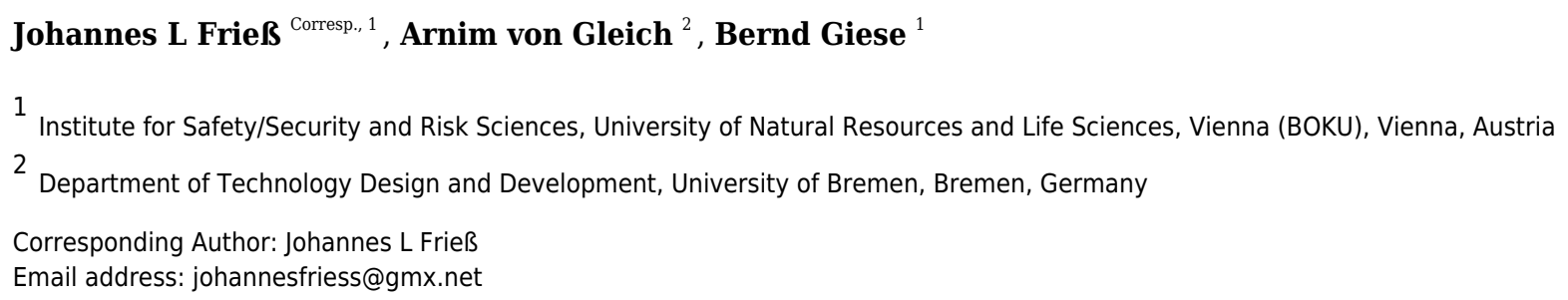

Compared to previous releases of genetically modified organisms (GMOs) which were primarily plants, gene drives represent a paradigm shift in the handling of GMOs: Current regulation of the release of GMOs assumes that for specific periods of time a certain amount of GMOs will be released in a particular region. However, now a type of genetic technology arises whose innermost principle lies in exceeding these limits - the transformation or even eradication of wild populations. The invasive character of gene drives demands a thorough analysis of their functionalities, reliability and potential impact. But such investigations are hindered by the fact that an experimental field test would hardly be reversible. Therefore, an appropriate prospective assessment is of utmost importance for an estimation of the risk potential associated with the application of gene drives. This work is meant to support the inevitable characterization of gene drives by a comparative approach of prospective technology assessment with a focus on potential sources of risk. Therein, the hazard and exposure potential as well as uncertainties with regard to the performance of synthetic gene drives are addressed. Moreover, a quantitative analysis of their invasiveness should enable a differentiated evaluation of their power to transform wild populations. 


\section{Gene drives as a new quality in GMO releases - a 2 comparative technology characterization}

3

4 Johannes L. Frieß $\beta^{1,}$, Arnim von Gleich ${ }^{2}$ and Bernd Giese ${ }^{1}$

5

$6 \quad{ }^{1}$ University of Natural Resources and Life Sciences, Vienna (BOKU), Institute of

7 Safety/Security and Risk Sciences, Vienna, Austria

$8{ }^{2}$ University of Bremen, Department of Technology Design and Development, Bremen, Germany 9

10 Corresponding Author:

11 Johannes Frie $\beta^{1}$

12 Dänenstraße 4, 1050 Vienna, Austria

13 Email address: Johannes.Friess@boku.ac.at 
15

16

17

18

19

20

21

22

23

24

25

26

27

28

29

30

31

32

33

34

35

36

37

38

39

40

41

42

43

44

45

46

47

48

49

50

51

52

53

54

\section{Abstract}

Compared to previous releases of genetically modified organisms (GMOs) which were primarily plants, gene drives represent a paradigm shift in the handling of GMOs: Current regulation of the release of GMOs assumes that for specific periods of time a certain amount of GMOs will be released in a particular region. However, now a type of genetic technology arises whose innermost principle lies in exceeding these limits - the transformation or even eradication of wild populations. The invasive character of gene drives demands a thorough analysis of their functionalities, reliability and potential impact. But such investigations are hindered by the fact that an experimental field test would hardly be reversible. Therefore, an appropriate prospective assessment is of utmost importance for an estimation of the risk potential associated with the application of gene drives. This work is meant to support the inevitable characterization of gene drives by a comparative approach of prospective technology assessment with a focus on potential sources of risk. Therein, the hazard and exposure potential as well as uncertainties with regard to the performance of synthetic gene drives are addressed. Moreover, a quantitative analysis of their invasiveness should enable a differentiated evaluation of their power to transform wild populations.

\section{Introduction}

In recent years, innovation in genetic engineering brought forth a number of technologies to manipulate the fate of entire wild type populations. These technologies rely on a supermendelian dissemination of genetic elements within a population of sexually reproducing animal or plant species via the germline and are identified as gene drives (GD). A number of natural mechanisms contribute to this notable capability. Sinkins \& Gould (2006) mentioned transposable elements, meiotic drive genes, homing endonuclease genes and Wolbachia as naturally occurring gene drives. A theoretical concept for gene drives as a method to drive a desired gene, or a set of genes into a population was already proposed in 1960 by Craig et al.: "Mass release of male-producing males might be used in control operations." (Craig, Hickey \& VandeHey, 1960). In those years the spread of chromosomal translocations was already proposed as a means of population control (Serebrovskii, 1940; Curtis, 1968). Hastings (1994) suggested to use so called "selfish genes" for that purpose and a practical implementation was explored with the use of the P-element for germline transformation of Drosophila melanogaster by Carareto et al. in 1997 (Carareto et al., 1997). Austin Burt in 2003 suggested to use homing endonucleases for the design of self-replicating drives (Burt, 2003). Gene drives propagate even if they confer a fitness penalty, or in other words "Mathematically, drives are initially favoured by selection [...] if the inheritance bias of the drive exceeds its fitness penalty." (Noble et al., 2018 , p. 201). Some secure their dissemination passively so that only offspring carrying genetic information of the drive will survive or be fertile. Akbari et al. called this type of mechanism "selective embryonic lethality" (Akbari et al., 2015). Others actively overcome the limitations of the Mendelian inheritance pattern by a distortion of allelic segregation i.e. fragmentation of chromosomes, for example resulting in an altered sex ratio. Active drives may also copy their 
55

56

57

58

59

60

61

62

63

64

65

66

67

68

69

70

71

72

73

74

75

76

77

78

79

80

81

82

83

84

85

86

87

88

89

90

91

92

93

94

genetic information between homologous chromosomes resulting in homozygous offspring. Such approaches were termed ,active genetics“ Gantz and Bier (2015). If organisms have a comparably short generation time, as e.g. insects, then within a few months, a large share of the population could express a new gene drive-transmitted trait. In particular, very invasive s may be able to impose functionalities that otherwise would not be prevalent onto entire populations.

Besides the opportunity to genetically modify entire wild populations, gene drives are discussed and partially already designed for the suppression of populations. If for example the functionality mediated by the drive consists in infertile offspring, an entire population may disappear.

Currently, multiple applications are under consideration. Especially malaria- or dengue-carrying mosquitoes are potential targets. In agriculture, weeds and crop pests could be eradicated or endangered species could be immunized against pathogens using a GD. Two potential applications of gene drives even serve issues of nature conservation, namely the eradication of invasive animal or plant species (Webber, Raghu \& Edwards, 2015) and the conservation of endangered species (Esvelt et al., 2014; Ledford, 2015; European Commission \& Scientific Advice Mechanism, 2017). Although discussed in the 2016 NASEM report on gene drives (National Academies of Sciences, 2016), the idea to recover the sensitivity of pest species to pesticides or to remove transgenic resistances from feral populations have not been pursued in the scientific literature of the following years.

So far, gene drives have not yet been released, but the discussion is gaining momentum (Hochkirch et al., 2017; Courtier-Orgogozo, Morizot \& Boëte, 2017; Emerson et al., 2017). In particular the development of new GD variants is closely linked to the upswing that genome editing methods have taken by the increasing application of CRISPR/Cas (Clustered regularly interspersed palindromic repeats and CRISPR-associated protein) gene scissors (Gantz \& Bier, 2015; Gantz et al., 2015).

A variety of different GD approaches has been developed in recent years. While some are genetically engineered, others are based on naturally occurring mechanisms that bias heredity. Gene drives currently in development or already applied in caged tests encompass: Meiotic Drives (autosomal- or Y-linked X-shredder), Maternal Effect Dominant Embryonic Arrest (Medea) systems, Underdominance-based systems and Homing Endonuclease Genes (HEG) based systems, especially CRISPR/Cas. Others, like Killer-Rescue are currently only theoretically explored.

Until now, there is no option to retrieve a GD once released into the environment. And biosafety approaches tend to be more adapted for genetically modified plants. It is therefore important to develop approaches for risk assessment and risk management which consider the specific properties of plants and animals. Moreover, in conventional GMO-applications (mostly plants), the GMOs are released into the highly artificial habitats of agricultural fields. Furthermore, GMplants are reaped annually and thereby retrieved. Releases are designed with the intention to avoid the spread and invasion of natural populations. In all these issues gene drives organisms represent the opposite: they are designed to spread, invade and persist for multiple generations or even indefinitely in wild habitats. The differences between conventional GMOs and GDOs were 
95

96

97

98

99

100

101

102

103

104

105

106

107

108

109

110

111

112

113

114

115

116

117

118

119

120

121

122

123

124

125

126

127

128

129

130

131

132

133

134

well examined by Simon, Otto \& Engelhard (2018). However, with regard to gene drives in plants, exposure may be enhanced or difficult to control due to the spread of pollen or a comparably large number of hybridisation partners. Furthermore inheritance and spread of a GD in plants can be complicated by selfing, dioecy and polyploidy. Although there are many ideas to restrict their spread and invasion or even to alleviate adverse effects, a complete reversal and restoration of the pre-existing state (and genotype) seems impossible to date. So-called selflimiting approaches may pose a partial exception to this as their mode of action is developed to result in a decrease of the gene drive's prevalence within a population. However, at the current state of knowledge a released GD has to be regarded as irretrievable. It is therefore necessary to further advance prospective approaches for the assessment of risk-relevant functionalities (and the associated uncertainties) of drive systems considered for release. The present work will address this issue in a comparative characterization of GD techniques.

\section{Materials \& Methods}

\section{Prospective technology characterization}

An early assessment of new technologies with regard to potential sources of risks is important and useful as an approach to operationalize the requirements of precaution, because in the case of severe concerns in an early innovation phase mitigations, corrections and course changes to alternative development paths are more easily directed. In the first stages of an innovation process, the outlines of a technology are probably already known, but possible applications and affected systems are usually still vague. However, approaches for an early assessment of potential hazards and exposure as well as an assessment of different dimensions and forms of lacking knowledge regarding hazards and exposure already exist (Ahrens et al., 2005; Steinfeldt et al., 2007; Owen et al., 2009; Giese \& von Gleich, 2015; Linkov et al., 2018). The underlying hypothesis in our approach is, that the range and the forms of non-knowledge are not 'just there', but are to a large extend produced by the character of the technology. Depth of technological intervention and also the intensity of intervention are the first criteria to investigate the sources, the range and forms of lacking knowledge (ranging from uncertainties to ignorance) by scrutinizing their technological origin. Depth of intervention as a criterion for prospective technology assessment was originally outlined as 'Eingriffstiefe' by von Gleich, (1989), based on thoughts from Anders (1956) and Jonas $(1979,1985)$. It applies to technologies based on the mathematical and experimental sciences for which the differentiation between the level of the phenomena and the level of natural laws (the logic behind the phenomena) is constitutive. Technologies that apply their technological intervention not at the level of phenomena but on structures that are able to control these phenomena, like atoms and fundamental particles or molecular structures and genes, generate a much higher power and farther reaching consequences. Thus, the depth of intervention can be identified as a source of technological power and range. The criterion 'depth of intervention' has proven to be applicable in synthetic chemistry (Böschen, Lenoir \& Scheringer, 2003), in nanotechnology (Rip, 2006) and synthetic biology (Grunwald, 2016). Similar conceptualizations can be found in Deutscher Ethikrat 
135 (German Ethics Council, 2011) and in Engelhard, Bölker \& Budisa (2016). The German Ethics

136 Council translates 'Eingriffstiefe' as "degree of manipulation" and focuses on three Aristotelian

137 "ontological" concepts: matter and form, ontogenesis and capabilities Deutscher Ethikrat

138 (German Ethics Council, 2011, p. 68 ff).

139

140

High power and high range of exposure due to a corresponding depth of intervention lead to a

141 large extend of non-knowledge concerning possible effects. In order to provide additional information on the frequency and the corrigibility of the expected effects, the quantitative aspects of the use of the technology (intensity of intervention i.e. quantity and frequency of its use), its reliability in practice, the probability of failure and finally possible ways of limiting harm in case of failure have to be analysed.

146 The aim of a prospective technology characterization is not to identify every possible adverse effect of technologies. Instead, it should provide a basis for decision-making in the context of the precautionary principle (The Rio declaration on environment and development, 1992; Commision of the European Communities, 2000; United Nations, 2000; European Environment Agency, 2002). "The precautionary principle enables decision-makers to adopt precautionary measures when scientific evidence about an environmental or human health hazard is uncertain and the stakes are high" (European Parliament Think Tank, 2015) The precautionary principle legitimates precautionary action in cases when it is unwarrantable to wait until a risk is clear and proven, because a probably occurring disaster will then not be controllable. Preconditions for precautionary action are therefore: a) lack of knowledge (from uncertainty to ignorance), b) comprehensible reasons for concern (affecting extremely powerful and/or far reaching consequences), c) a rudimentary cost-benefit analysis (in which e.g. medical applications with little less risky options are rated higher than applications in the food chain with plenty alternatives), d) adequate measures (reaching from containment over substitution by less problematic alternatives to moratorium) (Fischer, Jones \& von Schomberg, 2006). Our approach to operationalize the precautionary principle is based on technology characterization with the focus on technological interventions, functionalities and properties that generate high potentials for far reaching, by-trend-irreversible and global effects. Although a further differentiation of hazard related effects is highly dependent on the particular design of a drive, predictions on the extended range as the most remarkable quality in comparison to previous transgenes are already possible. We will therefore exclude an assessment of the specific technological power and restrict our analysis to functionalities of gene drives which are relevant for exposure. Prospective technology characterization thus considers at least the following criteria:

\section{Technological range}

171 For gene drives in general, the depth of intervention is much higher than in approaches for population control which are not based on genetic modifications. Gene drives constitute a manipulation of the very basis of organisms, their genetic characteristics, which enables a potentially high technological power and range. The technological range describes the potential 
175 spatio-temporal consequences of a GD, considering its lasting persistence in a population as well

176 as the range with which it could spread across populations. Depending on their mode of action,

177 gene drives theoretically have varying potentials to invade populations. Some approaches may

178 even be self-limiting and disappear or at least only persist for a limited number of generations,

179 whereas others are self-sustaining and - in addition to their ability to persist - may invade into

180 non-target wild type populations (cp. Alphey, 2014). For this analysis the partial and transient

181 occurrence of a drive is considered as a comparably low range, while the permanent replacement

182 of a population with genetically altered specimens is considered a high range.

183 Intensity of intervention

184 The intensity of intervention as mass or frequency of released organisms describes the necessary

185 quantity of interventions to drive a desired trait into a targeted population. An approach requiring

186 the released organisms to outnumber the wild type organisms or a series of releases would score

187 as high intensity and if an initially lower percentage of the population is sufficient, it would

188 correspond to a low intensity.

189 Reliability of the technology

190 Reliability describes the probability of failure of the technology with regard to its intended use.

191 Important reliability issues are e. g. linkage-loss of the cargo gene and its driver system, the

192 generation of resistances in the target population, coevolution of a pathogen and system decay

193 (Alphey, 2014).

194 Corrigibility or limitation of damage in case of failure

195 This criterion addresses an important aspect of risk management. Can the damage of a failed GD

196 be reversed by any means and if so, how laborious are they, compared to the initially released

197 construct or system? For some GD-technologies it is claimed that they can be somewhat

198 remedied by a release of wild type organisms. But such an endeavour would not really reverse

199 the damage done. Even more difficult to estimate are corrective actions such as a reversal drive,

200 which on one hand relies on the release of a second generation GD to remedy the failures of the

201 first. But on the other hand, the gene pool of the target population in any case retains transgenic

202 elements.

203 The criteria of prospective technology characterization including corresponding GD-specific

204 parameters and examples are shown in Fig 1.

205

206 Deterministic recurrence-based model for gene drive inheritance

207 The model was based on the inheritance schemes of the various GD techniques. The probability

208 of the occurrence of a certain genotype was multiplied by its respective fitness. Random mating

209 based on the respective genotypes' percentages within the infinite population was assumed.

210 Genotype fitness and initial population percentage can be chosen by the user. To calculate the

211 invasiveness of the GD techniques, the variation of the fitness and population percentage

212 parameters were automated for a given generation and depicted in a colour-coded graphic where

213 population percentages are assigned different colours, depending on chosen thresholds. See

214 supporting information for further details. 


\section{Results}

217 Comparative prospective technology characterization of gene drives

218 In the following, meiotic drives, Killer-Rescue-systems, the Medea-approach, Underdominance

219 as well as Homing Endonuclease-based gene drives are introduced and discussed according to 220 the criteria of prospective technology characterization.

221 As a means to compare the different GD-technologies, a rough assessment according to the 222 criteria mentioned above was applied. Regardless of the fact that such a classification has to be 223 further differentiated in subsequent studies, it has to be noted that this rating only refers to the 224 comparative approach between the technologies included in this study and does not reflect any 225 conclusion on their absolute impact.

226

\section{$\mathrm{X}$-Shredder as an example for meiotic drives}

Meiotic Drives (MD) consist of selfish genetic elements which cause a distortion of allelic segregation that results in a bias of the frequency of Mendelian inheritance. For instance, the Mendelian segregation frequency of $50 \%$ is distorted up to $70 \%$ in Zea mays (Lindholm et al., 2016; Australian Academy of Science, 2017). Other MDs have been reported for Drosophila melanogaster (segregation distorter [SD] system) (Larracuente \& Presgraves, 2012), the mouse Mus musculus (t-haplotypes, causing a transmission ratio distortion) (Silver, 1993), Zea mays (abnormal chromosome 10 [Ab10]), which affects Gonotaxis, distorted sex ratios in Silene species (Taylor, 1994) and mosquitoes. In the latter, MDs are naturally occurring in Aedes aegypti (Craig, Hickey \& VandeHey, 1960) and Culex pipiens (Sweeny \& Barr, 1978). A major drawback of MDs consists in the fact that the fitness of other alleles at the same locus, which do not bias transmission, and alleles linked to them, is reduced (Lindholm et al., 2016). For gene drives, a particularly interesting MD is the so called X-Shredder, which causes fragmentation of the $\mathrm{X}$ chromosome by nucleases during male meiosis. Thereby only Y-bearing sperm can produce viable offspring, which is of course male (Newton, Wood \& Southern, 1976). An autosomal X-shredder can be regarded as self-limiting, a Y-linked X-shredder as selfsustaining (Burt, 2003; Burt \& Trivers, 2006; Deredec, Burt \& Godfray, 2008). A Y-linked Xshredder can invade adjacent populations or species with incomplete mating barriers, therefore widespread effects may be anticipated (Alphey, 2014). Galizi et al. (2014) published a synthetically engineered $\mathrm{X}$-shredder aiming at spermatocyte meiosis in Anopheles gambiae, producing mainly Y-chromosome-carrying sperm, causing a male bias of up to $95 \%$. A distortion of the sex ratio is a penalty to fitness, which may in extreme cases lead to a population's extinction. Although rarely, in Drosophila, sometimes $100 \%$ female progeny is achieved. Therefore, this trait is highly selected against. Hence, meiotic drive-based extinction has never been observed in natural populations (Helleu, Gérard \& Montchamp-Moreu, 2015). For this study we focus on the self-sustaining variant of the Y-linked X-Shredder.

\section{Range of X-Shredder intervention:}


255 The X-Shredder approach potentially constitutes a self-sustaining GD. A male bias of up to $95 \%$ 256 would cause a major population suppression. Moreover, a population consisting mainly of males 257 is much more likely to migrate in search of females. Taken together, there is some evidence that 258 the technological range of X-Shredder drives can be regarded as high.

259 Intensity of X-Shredder intervention:

260 To obtain a rapid effect, the X-Shredder approach requires a mass release of males. The 261 necessary intensity of the technological input can thus be regarded as high. However, over

262 multiple generations even a small release size could theoretically suffice to replace a population, 263 dependent on the fitness of the gene drive organism (GDO).

264 Reliability of the X-Shredder technology

265 Based on the small number of available publications on X-Shredder approaches in a preliminary 266 comparative assessment of gene drives, key points of error encompass:

267 - lowered fitness of laboratory-reared GM insects due to inbreeding (colony effect)

268 - selection against the fitness burden

269 - errors in the release: wild types, and phenotypic male wild types carrying the non-

270 functioning construct (would reduce the suppressive effect)

271 Possibilities for damage limitation caused by X-Shredder technology:

272 There is no possibility to directly remedy the damages obtained from an X-Shredder release.

273 This makes the technique highly problematic, it is built to first invade and replace, followed by

274 immediate suppression, due to the lack of females. Its low threshold further exacerbates the

275 handling of Y-linked X-Shredder gene drives.

276

277

\section{Killer-Rescue}

278

279

The Killer-Rescue system was first proposed by Gould et al. in 2008, it consists of two unlinked loci one encoding a toxin (killer allele), the other encodes an antidote (rescue allele) (Gould et

280

281 al., 2008). Thereby, the toxin and antidote could consist of miRNAs and a recoded gene or a toxic protein and toxin-inhibiting enzyme. Furthermore, a cargo gene can be fused to the antidote

282 gene. Homozygous carriers for both genes would be mass-released into wild populations,

283 offspring inheriting the killer allele but not the rescue allele would be non-viable. Since both

284 alleles are not linked in their inheritance, the killer allele will be quickly selected from the

285

286 population, while the rescue allele confers a clear fitness gain and will increase in its prevalence.

287 As soon as the killer allele completely disappeared from the population, so will the rescue allele's fitness gain. As a consequence, the rescue allele will again decline in its prevalence,

289 unless the cargo gene confers a gain in fitness. The Killer-Rescue system is highly dependent on

290 the fitness of the rescue and cargo genes which determines the time until the cargo genes are

291

292 eliminated from a population (Marshall \& Akbari, 2017).

\section{Range of Killer-Rescue intervention:}


293 The Killer-Rescue system is not by design a suppression drive. Considering the technological

294

295

296

297

298

299

300

301

302

303

304

305

306

307

308

309

310

311

312

313

314

315

316

317

318

319

320

321

322

323

324

325

326

327

328

329

330

331

332

range, Killer-Rescue, due to its non-persistent quality, its therefore limited probability of contamination of other populations and relatively high invasive threshold scores as low.

\section{Intensity of Killer-Rescue intervention:}

The Killer-Rescue system potentially reduces the population size only in dependence on the number of released GDOs. According to model scenarios by Gould et al. (Gould et al., 2008), this drive-system is reliant on a high number of released carriers of up to a ratio of GDOs to wild types of 2:1. Although this ratio is much lower than reported for other mass release-dependent techniques, the wild type population most likely has to be outnumbered to be successful.

Therefore, mass and frequency of Killer-Rescue are regarded as high.

\section{Reliability of the Killer-Rescue technology:}

For Killer-Rescue based drives, reliability may be impaired by:

- $\quad$ lowered fitness of laboratory-reared GM insects due to inbreeding (colony effect)

- the selection against the fitness burden (resistance formation or toxin-inactivation).

- Linkage loss between rescue and cargo gene

- Natural evolution of an antidote or inactivation of the killer allele

\section{Possibilities for damage limitation caused by Killer-Rescue technology:}

Since it is expected that the Killer-Rescue system has a high invasion threshold (although lower than that of other threshold-dependent techniques) the most feasible option to limit the spread of this GD is a release of wild types (Gould et al., 2008). Additionally, it would be recommendable to use miRNA as a killer allele in order not to give the carrier-organisms a toxic functionality.

This system is designed to be a self-limiting modification GD in which, if the cargo gene bears a fitness penalty, its prevalence in the population would decrease after a number of generations.

There is a possible variant where multiple copies of the killer allele are incorporated into the GDOs' genome, enhancing the selective benefit of the rescue allele. A particular benefit of the technique is that it is easy to design and engineer (Gould et al., 2008).

\section{Medea (maternal-effect dominant embryonic arrest)}

The term Medea is an acronym pointing at the sorceress in Greek mythology who killed her own children. This indication is accurate, as a Medea selfish genetic element consists of two chromosomally-located tightly linked transgenes: one that encodes a (miRNA-) toxin deposited in all embryos of Medea-bearing mothers, and a second that encodes an antidote (a silencing resistant recoded gene without the miRNA-sequence) active in the zygote (Akbari et al., 2014). Therefore, only Medea-bearing offspring (hetero- or homozygous) survives. This maternally induced lethality of wild type offspring not inheriting a Medea allele grants an ability to invade populations.

The Medea elements were first discovered in Tribolium flour beetles (Beeman, Friesen \& Denell, 1992) and have also been reported in mice (Peters \& Barker, 1993; Weichenhan et al., 1996). The only published synthetic Medea constructs (Medea myd88, o-fut 1 and dah) have been 
333 inserted on an autosomal chromosome in Drosophila melanogaster. The myd88 construct has

334 also been introduced into the genome of the cherry fruit fly, D. suzukii (Buchman et al., 2018).

335 myd88 is a maternally expressed gene required for embryonic dorso-ventral pattern formation. If

336 Medea is located on the $\mathrm{X}$ chromosome in a $\mathrm{X} / \mathrm{Y}$ male heterogametic species, Medea is predicted

337 to spread to allele fixation, with wild type alleles being completely eliminated (Akbari et al.,

338 2014).

339 Medea organisms exhibit a high-frequency stable equilibrium when the transgenic construct is

340 associated without any fitness cost (Gokhale, Reeves \& Reed, 2014). The fitness costs of

341 homozygote Medea Drosophila were estimated to be $27.3 \%$ and $17.4 \%$, respectively, for two

342 different targeted genes. In lab trials, where $25 \%$ of the original members were homozygous for

343 Medea, the gene spread through the entire population within 10 to 12 generations. Observations

344 indicate that a single copy of each Medea toxin is sufficient to induce $100 \%$ maternal-effect

345 lethality and a single copy of each rescue transgene is sufficient to rescue normal development of

346 embryos derived from mothers expressing one or two copies of the toxin. (Akbari et al., 2014)

347 Until now, attempts to establish a Medea system for Aedes aegypti were not successful.

348 Currently, Medea is planned to be applied for population control of the cherry fruit fly (spotted-

349 wing fruit fly Drosophila suzukii) in California (Regalado, 2017). Two considered approaches

350 are to either target female fertility genes or to alter the ovipositor of the flies to make them

351 unable to puncture the ripening cherries. Buchman et al. (2018) found pre-existing native

352 resistances against the miRNA toxins of their construct in 5 out of 8 examined D. suzukii strains.

353 Together with the high fitness penalties conferred by the construct the Medea GD now has to be

354 considered a high threshold drive, that when conferring a large fitness penalty will only be

355 transiently maintained in the population without supplemental releases. In a mathematical model

356 for the myd 88 construct in the cherry fruit fly, a fitness cost for heterozygotes of $28 \%$ and $65 \%$

357 for homozygotes were assumed (Buchman et al., 2018).

358

359 Range of Medea intervention:

360 Dependent on the cargo gene and fitness penalty, Medea drives will either drive to fixation or

361 will be selected from the population after a number of generations and have therefore only a

362 potentially transient effect on population size. However, due to its potentially high invasiveness

363 and the ability to spread into non-target populations its range and thus its potential of exposure

364 should be regarded as high.

365 Intensity of Medea intervention:

366 It would not require many genetically-altered organisms to drive a trait to fixation if the fitness

367 penalty is low. However, as demonstrated by Buchman et al. (2018), due to the pre-existing

368 resistances and high fitness penalties it is more likely that multiple mass releases are required for

369 a successful drive (Marshall et al., 2017). Therefore, a high intensity of intervention is

370 considered for Medea gene drives.

371 Reliability of the Medea technology:

372 Key points of error encompass: 
373 - lowered fitness of laboratory-reared GM insects due to inbreeding (colony effect)

374 - the selection against the fitness burden (resistance formation by toxin-inactivation or

375 selection for pre-existing resistances).

376 Possibilities for damage limitation caused by Medea technology:

377 A potential measure would be to release a second generation Medea GD. This would introduce a

378 new toxin-antidote combination as well as the antidote for the first generation toxin. Although

379 the suppressive effect of Medea may be stopped by this approach, it introduces even more

380 persisting GMOs into the ecosystem.

381

382

\section{Underdominance (UD)}

383

384

Underdominance, also known as heterozygote inferiority is a genetically engineered GD

385 technique. So far, there are two different approaches called UD ${ }^{\text {mel }}$ (Akbari et al., 2013) and

386

387

388

389

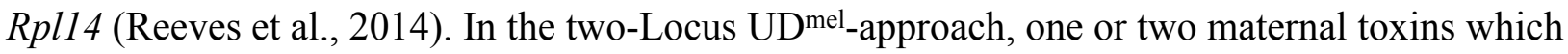
target maternal genes essential for embryonic development (oogenesis and embryogenesis) are introduced within two constructs. Each construct consists of a maternal toxin gene and an embryonic antidote. However, the antidote to each toxin is located on the other construct. One

390

391 construct encompasses the genes for toxin A and antidote B, the second construct holds toxin B

392 and antidote A. An organism must receive both antidotes to the maternally administered toxins to be viable. Therefore, UD heterozygotes have a lower fitness than homozygotes (Reeves et al.,

393

394

395

396

397

398

399

400

401

402

403

404

405

406

407

408

409

410

411

412 2014). When a UD-female heterozygous for both constructs mates with a wild type male, $25 \%$ will be heterozygous for both constructs, while $25 \%$ of offspring will be non-viable wild types, and $50 \%$ will be non-viable due to the lack of one of the necessary antidotes. With myd88, dah and o-fut-1 (Akbari et al., 2013) the toxins of Underdominance constructs may be the same as utilized in the Medea technology. Since the toxins are administered maternally, a release of wild type males into a replaced Underdominance population would lead to a population crash, as all offspring would inherit the wrong antidote (Akbari et al., 2013).

The RpL14-approach, utilizes a haploinsufficient cytoplasmic ribosomal protein. One allele of Rpl14 is replaced by a toxin-antidote combination of the same gene. The construct consists of a miRNA-gene against the targeted gene and a recoded variant of the gene, immune against the miRNA. An Underdominance GD requires a high threshold release (National Academies of Sciences, 2016). For the RpL14 construct, this threshold is estimated to be as high as $61 \%$ of the total population (Reeves et al., 2014). Therefore, an unintended underdominant population transformation can theoretically be mitigated where it is realistically possible to release sufficient wild type individuals to traverse the unstable equilibrium in the lower frequency direction (Gokhale, Reeves \& Reed, 2014).

\section{Range of Underdominance intervention:}

In comparison to the Medea approach, the range of Underdominance is estimated to be low, due to its higher invasion threshold (Alphey, 2014). 
413 Intensity of Underdominance intervention:

414 Since an application of this technology is even more frequency-dependent than a Medea

415 approach, requiring even greater mass releases, its intensity is also rated as high.

416 Reliability of the Underdominance technology

417 The intended functionality of Underdominance-drives may be impaired by

418 - lowered fitness of laboratory-reared GM insects due to inbreeding (colony effect)

419 - the selection against the fitness burden

420 Possibilities for damage limitation caused by Underdominance technology:

421 Should the release of underdominant specimen show to eventually lead to an undesired

422 population replacement (or other undesired side effects), a wild type release could theoretically

423 shift the population percentage beneath the necessary threshold and thereby mitigate the GD.

424

425

426

427

428

429

430

431

432

433

Homing Endonuclease Genes (HEG)

HEGs are selfish genetic elements. But different from transposable elements, they code for a restriction enzyme with a target sequence of 20-30 bp. The HEG is nestled within its own recognition site. An expressed homing endonuclease-protein finds intact recognition sites and cuts them. Then the selfish genetic element relies on the DNA-repair mechanism of homologous recombination which copies the HEGs code and inserts it into the cut-site on the homologous chromosome. In the following we will focus on the use of the CRISPR/Cas9-system for the construction of HEG-based drives.

434

435

436

437

438

439

440

441

442

443

444

445

446

447

448

449

450

451

\section{CRISPR/Cas9}

CRISPR stands for Clustered Regularly Interspaced Short Palindromic Repeats, while Cas stands for CRISPR-associated protein. Both components originate from an adaptive immune system of bacteria and archaea. Cas9 is a ribonucleoprotein (RNP), able to bind guide RNAs (gRNA), aka crRNA that specifically recognizes and binds to the target sequences (20 nucleotides) (Doudna $\&$ Charpentier, 2014). The target DNA-sequence must contain a protospacer adjacent motif (PAM) with the sequence NGG for the Cas protein to cut (Jinek et al., 2012)(Jinek et al., 2012; Doudna $\&$ Charpentier, 2014). The cut takes place three nucleotides upstream of the PAM, causing a blunt end double strand break (DSB). This technology can be used to cause deletions as well as insertions, relying on homologous recombination (Doudna \& Charpentier, 2014). The guide RNAs serve target site recognition which makes this technology cheaper and easier to customize, while also being more effective (Jinek et al., 2012; Doudna \& Charpentier, 2014) than conventional genome editing techniques and are thus also suitable as a GD. Figure 2 illustrates the mode of action of such a GD. The most probable application would utilize a CRISPR/Cas9mediated GD system inheriting a cargo gene to the vast majority of its offspring, which would burden the population's fitness by e.g. targeting the organisms' fertility. However, low rates of homology directed repair (HDR) may hinder the spread of the drive (Unckless, Clark \& Messer, 2016).

Peer) reviewing PDF | (2018:11:32627:1:2:NEW 14 Mar 2019) 
452 A non-homologous repair of the cut site by Non-Homologous End Joining (NHEJ) or

453 Microhomology-Mediated End Joining (MMEJ) reduces the conversion rate because these

454 alternative mechanisms often cause mutations or deletions at the target site of the endonuclease.

455 Usually when a cut is not repaired by HDR, the result is a drive resistant allele. Depending on the

456 genomic location, HDR vs. NHEJ efficiency could be as low as $\sim 10 \%$ (Lin \& Potter, 2016). To

457 reduce these events, CRISPR/Cas9 could be used to enhance HDR gene expression and repress

458 NHEJ-genes. This could be achieved by the inclusion of HDR-genes and NHEJ-repressor genes.

459 Furthermore, the generation of nucleases creating sticky-end overhangs as opposed to blunt ends

460 may optimize the repair in the target organism. The rate of HDR depends on the species, cell

461 type, developmental stage, and cell cycle phase. For example faithful copying was achieved with

462 up to $97 \%$ efficiency in mosquitoes but only $2 \%$ in fruit flies. (Esvelt et al., 2014)

463 Other studies yielded average homing rates of 56\% (KaramiNejadRanjibar et al. 2018) and 97\%

464 (Gantz \& Bier, 2015) in Drosophila and 98.8\% in Anopheles stephensi (Gantz et al., 2015) and

465 even $99 \%$ in wild yeast (DiCarlo et al., 2015a).

466 Homing resistant alleles may as well occur due to random mutations, affecting the recognition

467 site of the gRNA or the PAM. A general option to prolong the activity of a CRISPR/Cas-based

468 drive in cases of target site mutagenesis is therefore to engineer multiple attack loci for the

469 CRISPR/Cas9-system in the genome (multiplexing). Each additional site reduces the chance of

470 mutation in all attacked alleles. However, very large populations - such as those of some insects

471 - might require unfeasibly large numbers of gRNAs to prevent resistance.

472 First observations suggest that resistance can also be the result of a so called "dominant maternal

473 effect" (Ping, 2017). It is assumed that Cas9 deposits in the oocyte cause early cuts in the

474 genome of the sperm cell, shortly after fusion. Upon fertilization, if sufficient Cas9 (and gRNA)

475 is in the cytoplasm of the zygote which is homo- or heterozygous for the GD the CRISPR/Cas

476 complex finds and cuts its recognition sites in the sperm's genome before the homologous

477 female genome is close enough to be recruited for homologous recombination. Without a

478 homologous template the cuts are then repaired by NHEJ and thus a resistant allele may arise. In

479 such an event, the number of gRNA variants is meaningless. Propagation of resistant individuals

480

481

482 may be prevented by targeting essential genes (Noble et al., 2017).

483 In comparison to other GD techniques, CRISPR/Cas9-based GD systems are unique due to their 484 potential to generate homozygous offspring with wild types. Since these drives seem to be self485 sustaining for multiple generations despite a fitness burden their range can be regarded as high.

486 Intensity of CRISPR/Cas9-gene drive intervention:

487 Due to its non-mendelian, copy-based inheritance pattern, CRISPR/Cas9-gene drives are nearly 488 frequency-independent. Therefore, this technology's necessary frequency is low in comparison 489 to other techniques.

490 Reliability of the CRISPR/Cas9-gene drive technology:

491 Failure of the CRISPR/Cas9-gene drive technology may be a result of: 
492 - lowered fitness of laboratory-reared GM insects due to inbreeding (colony effect)

493 - the selection against the fitness burden

494 - NHEJ and MMEJ instead of HDR

495 - incomplete or imperfect copying during HDR (if the deletion preserves the reading

496 frame, it leads to a homing-resistant allele (Marshall et al., 2017))

497 - off-target effects (unspecific binding of gRNA causes unintended insertions at different

498 loci)

499 - on-target misinsertions (unwanted genes or gene fragments are inserted into the target

500 locus, instead of or additional to the desired genes) sometimes gRNA sequences are inserted (Li

501 et al., 2016).

502 - emergence of homing resistant alleles due to random target site mutagenesis

503 - sequence polymorphisms (resistance due to genetic variations within a species. To

504 overcome this problem multiple gRNA variants can be added to the CRISPR/Cas cassette)

505 - intragenomic interactions (the distance of gRNA target sites may affect homing rates

506 (Marshall et al., 2017)).

507 - maternal effects (Ping, 2017).

508 - release of phenotypic wild types carrying the non-functioning construct (would reduce

509 the suppressive effect and could constitute a persistently GD-resistant sub-population).

510 Possibilities for damage limitation caused by CRISPR/Cas9-gene drive technology:

511 As a potential approach to reverse detrimental damages caused by CRISPR/Cas9-gene drives the

512 (mass) release of a secondary drive was suggested, a rescue drive which cuts out the cargo gene

513 and forms a resistant locus (Esvelt et al., 2014). This however, would also mean a population

514 replacement, persistently introducing additional synthetic genetic material into the ecosphere as

515 the CRSIPR/Cas9-system would remain in the populations' gene pool. Some proposed drives to

516 limit the spread are:

517 - reversal (or overwriting) drive (Esvelt et al., 2014)

518 - immunizing drive (pre-emptively) to make populations immune to another drive (Esvelt

519 et al., 2014)

520 - split drive to serve local confinement (DiCarlo et al., 2015b)

521 - daisy chain drive for confinement in space and time (Noble et al., 2016)

522

523 Invasiveness of gene drives

524 The goal of this assessment is to describe the capacity of gene drives to achieve a population

525 replacement. To this end a simple population-genetic model was chosen that yields genotype

526 percentages as a function of fitness penalty and relative release size of GDOs (cf. (Gould et al.,

527 2008; Ward et al., 2011; Dhole et al., 2018). The chosen model enables a comparative analysis of

528 different GD systems where more specific models prohibit their investigation in a common

529 analytical frame due to the amount of necessary data and individual adaptions to the respective

530 types of GD.

531 
532 Many modelling approaches focus on CRISPR/Cas-mediated gene drives. Their focus may lie on 533 homing or conversion rates (Unckless et al., 2015; Eckhoff et al., 2017), some models also 534 emphasise spatial spread (Tanaka, Stone \& Nelson, 2017) and resistance formation (Drury et al., 535 2017). The second most modelled GD system is X-shredder, focussing again on spatial spread 536 (Beaghton, Beaghton \& Burt, 2016), shredding rate (Eckhoff et al., 2017), drive efficiency in 537 dependence of seasonal rainfall patterns (Lambert et al., 2018) or the tendency of suppression 538 drives to select for inbreeding (Bull, 2016). Other studies on Underdominance and daisy chain 539 (Dhole et al., 2018) or Killer-Rescue drive systems (Edgington \& Alphey) focus on migration 540 and invasion. Ward et al., (2011) explore possibilities of auto- and gonosomal Medea drive

541 systems. Lastly, combinations of GD systems were analysed by Huang et al. (2007) and

542 Gokhale, Reeves \& Reed, 2014).

543

544 As a basis, our underlying recurrence-based, deterministic model utilizes inheritance schemes in 545 a hypothetical population of infinite size. Therefore, it is impossible to achieve a population 546 suppression or eradication in this model. All genotypic subpopulations are regarded as relative 547 percentages of the whole population (for a more detailed explanation see supporting materials). 548 Two-locus Underdominance, Medea, a CRISPR/Cas-mediated GD including resistance allele 549 formation, Killer-Rescue and a Y-linked X-Shredder were chosen for a quantitative comparison 550 of their invasiveness. As positive and negative controls, the spread of two different transgenes 551 lacking the GD-specific functionality of super-Mendelian inheritance were calculated: a) female 552 specific release of insects carrying a dominant lethal (fsRIDL,(Fu et al., 2010) and b) a fitness 553 gain conferring transgene e.g. a pesticide resistance, respectively. For the calculations, the 554 following assumptions had to be made that should be taken into account for a critical discussion 555 of the presented results on the invasiveness:

556 - fsRIDL (negative control): Female lethality is 100\% regardless of zygosity. Cumulative 557 fitness penalty for each allele was assumed.

558 - Transgene with fitness loss/gain (negative/positive control): Cumulative fitness 559 loss/gain for each allele was assumed.

560 - X-Shredder: A Y-linked X-Shredder system with a male biased sex ratio of 95\% was 561 assumed according to Galizi et al., (2014). Since the ratio of females cannot decrease below 5\%, 562 due to the assumptions of our model, the thresholds were adapted for this approach to $7 \%$ and $56393 \%$ in the cross section computation.

564 - Killer-Rescue: Cumulative fitness penalties were assumed per allele regardless of killer 565 or rescue.

566 - Medea: Fitness penalty was assumed being cumulative for hetero- and homozygous 567 Medea-carriers.

568 - Underdominance: A two-locus autosome Underdominance system similar to UD ${ }^{\mathrm{mel}}$ 569 (Akbari et al., 2013) was modelled. Female-carriers kill offspring that do not inherit at least one 570 copy of each construct. It was assumed that heterozygosity for each of the Underdominance 571 alleles confers a $15 \%$ fitness penalty. Therefore, the double hetero UD genotype's fitness is $30 \%$ 
572 lower than that of the double homo genotype. Whereas homozygosity in one construct but lack

573 of the other results in half the fitness penalty of the double homozygotes.

574 - CRISPR/Cas-mediated gene drive: The homing rate was assumed to be $98 \%$ similar to

575 data presented by DiCarlo et al. (2015a). Resistance formation rates were assumed as the direct

576 reciprocals of the homing rates, i.e. $2 \%$. Fitness penalties were assumed to be half for

577 heterozygous GDOs. Each resistance allele was assumed to confer a $10 \%$ fitness penalty.

578 Homozygously resistant population percentages above $95 \%$ are depicted in green in the overlays.

579

580 Figure 3 shows positive and negative control approaches for the model as transparent overlays of

581 cross sections for up to 60 generations post release, in 5-generational steps. Negative controls are

582 represented by the complete fading of fsRIDL-carriers from a population within five generations

583 and the spread of a transgene which confers a fitness loss. The spread of a transgene which

584 confers a fitness gain represents a positive control. The blue areas represent combinations of

585 fitness and population percentage at a given generation post-release at which more than $95 \%$ of

586 the population is of wild type genotype. Red areas represent fitness and population percentage

587 combinations at given generations resulting in less than 5\% wild type genotypes in the

588 population.

589

590 Figure 4 shows the allele frequency of gene drives. The depicted generations post-release range

591 from 5 to a maximum of 60 , in 5-generational steps.

592

593 The cross-sections for invasiveness of the gene drives represent spread dynamics with clear

594 separation from negative controls as well as the positive control (cf. Fig 3). Calculations for a Y-

595 linked X-Shredder show a result which is markedly different from the other gene drives

596 investigated by this approach. Since it is linked to the Y-chromosome, X-Shredder females do

597 not occur and wild type females are only indirectly affected by it. But all males from a mating

598 with an X-shredder male are also X-Shredder males. An X-Shredder drive reaches an extremely

599 low invasion threshold. Though it takes a considerable amount of generations and the X-

600 Shredder males' fitness must not be below $70 \%$ if an invasion threshold below $10 \%$ should be

601 sufficient for a population invasion above 95\%. Interestingly, there seems to be a persistent

602 intermediate state for X-Shredder organisms with a fitness between $55 \%$ and $70 \%$ (white area in

603 Fig 4A). This intermediate state area even persists long beyond the shown 40 generations (tested

604 for up to 150 generation post release, see S11 Fig in supporting material). It is also important to

605 note that opposed to the other gene drive techniques examined here, the X-Shredder drive is

606 mainly applicable for suppression drives. However, as the model assumes an infinite population

607 size a population eradication cannot be modelled.

608 The Killer-Rescue cross sections show that even with no fitness penalty at least a release

609 threshold of $40 \%$ is required to achieve a population replacement. At high release percentages

610 the red areas are rescinding over the generations and in part even identify as blue areas in later

611 generations, this underscores the transient character of the Killer-Rescue system. 
612 For Medea obviously, the area of wild type individuals (blue) is growing faster than the area for 613 a population with less than 5\% wild type individuals (red). From this simple modelling approach, 614 it seems as if Medea could be a candidate for a temporally limited gene drive application which 615 gets lost after an active phase for e.g., 25 generations. According to the cross section overlay 616 shown in Fig 4 this can be achieved with lower invasion thresholds and for a longer time than 617 with an Underdominance-based drive system.

618 The two-locus Underdominance approach will end up in either a population replacement or the 619 loss of the gene drive construct more quickly than Medea. Also, UD is more threshold-

620

621

622

623

624

625

626

627

628

629

630

631

632

633

634

635

636

637

638

639

640

641

642

643

644

645

646

647

648

649

650 dependent. Even with the highest fitness for the Underdominance organisms, a release threshold of approx. $40 \%$ is required.

For a CRISPR/Cas-mediated GD, a homing rate of $98 \%$ was assumed. No other gene drive examined in this work occupies a comparably large red area for comparably low invasion thresholds and the given generations post release. This definitely makes CRISPR/Cas the most invasive technique in this model. Also noteworthy is the area in the low population percentage around $55 \%$ to $73 \%$ fitness which is considered a blue area after 5 generations but becomes occupied by the red area in later generations. This also indicates the high invasiveness of the technique due to its threshold-independence, as even with a release ratio below $5 \%$ of the population and a fitness down to $60 \%$ and $70 \%$, a population replacement can be achieved. For the CRISPR/Cas system, resistance formation is an important factor that reduces its transforming capacity. In our model, the inverse of the homing rate was assumed as the rate of resistance allele formation. Diagram F shows a green area, representing scenarios where a subpopulation of homozygous resistant organisms would make up more than $95 \%$ of the population. In either case, the resistance begins in the low fitness/high release percentage area and spreads into the medium fitness/low release percentage area, over 40 generations.

For a quantitative comparison of the gene drives investigated using the deterministic model, areas (i.e. the number of data points, see supplementary material) of wild type population percentage below $5 \%$ (red) and above $95 \%$ (blue) of a respective generation were divided by each other (red/blue). The resulting curves for the ratios over 60 generations post release are shown in Fig 5a. These curves show an asymptotic behaviour, with the exception of the CRISPR/Cas-mediated gene drive with resistance. In this special case, the number of data points of the green (resistance) areas are taken into account by subtraction from red areas. Omitting resistance allele formation results in an asymptotic behaviour similar to the other GD systems. The thresholds approached by the asymptotes can serve as a measure of the invasiveness of a technology. For a ranking of the drives investigated here, all thresholds are normalized to the highest threshold (CRISPR/Cas-based drive with no resistance formation) and listed in Table 1. Furthermore, in Fig 5b, the fitted curves for fitness loss and fitness gain transgenes are shown as positive and negative controls on a logarithmic axis. Note, the by far higher invasiveness of a transgene conferring a fitness gain. 


\section{Discussion}

652 A prospective and comparative characterization of gene drives depends on knowledge about the

653

654

655

656

657

658

659

660

661

662

663

664

665

666

667

668

669

670

671

672

673

674

675

676

677

678

679

680

681

682

683

684

685

686

687

688

689

690

mode of action and corresponding technical characteristics with regard to their functional effectiveness their potential to spread and expectable detrimental effects. As a prerequisite for further orientation on the impact (power and range) and potential ramifications of gene drives, common features of these technological approaches were selected for a comparative technology characterization as well as an analysis of factors (traits) which influence its impact, spread and invasiveness. In Table 2 the here discussed GD techniques are compared, summarizing this prospective assessment.

The comparative technology characterization revealed differences which presumably lead to different levels of expectable exposure. For instance, gene drives may employ different mechanisms to ensure super-mendelian inheritance, reaching from more or less passive drives, acting by selective embryonic lethality (Akbari et al., 2015) as Medea, Underdominance and Killer-Rescue or the biased segregation of sex chromosomes during meiosis (X-Shredder) to the high potential with regard to power and especially range that could be achieved with endonuclease-based gene drives using the CRISPR/Cas9-system. The release of GDOs carrying CRISPR/Cas-based drives is hard to assess due to their outstanding versatility and potential dynamics. It strongly depends on the chosen setup. Furthermore, the lack of knowledge about their potential behaviour is additionally increased by the fact that there is no naturally occurring comparative mechanism for this type of drive. Moreover, the list of potential sources of failure is comparably long for CRISPR/Cas9-based drives. With regard to exposure in particular actively replicating drives based on homing endonuclease genes (e.g., CRISPR/Cas9) are potentially highly effective in replacing a wild type population. This is reflected by the low initial intensity of intervention for CRISPR/Cas drives and its expected high range and invasiveness. The latter exceeds the results of all other drive types in our analysis. Of the passive drives, the Medeaapproach showed the highest invasiveness. The lowest invasiveness was found for Killer-Rescue drives. This result corresponds with the functionalities reported in the literature that lead to a classification as potential low range-drive in the technology characterization (Gould et al., 2008). Apart from this rough classification it is essential to investigate the average impact of resistance formation or detrimental mutations of these drives in experimental approaches over several generations in the same target species. Their performance and hence also a ranking with regard to exposure relevant functionalities may yield a different order. In the present work, resistance formation is only scarcely characterized due to preliminary information from first experiments or derived from the design of the drive. However, in particular CRISPR/Cas-drives tend to be afflicted with a comparably large number of sources for potential mutations of either their own genetic information or its target site. This instability is also the reason for a potential linkage loss of CRISPR/Cas drives with their cargo. However, a recent work by Kyrou et al. shows that resistance formation due to non-homologous end joining repair can be effectively circumvented by targeting highly conserved essential genes (Kyrou et al., 2018).

Peer) reviewing PDF | (2018:11:32627:1:2:NEW 14 Mar 2019) 
691 The more power and range are increased, the greater becomes the 'volume' of uncertainties and 692 ignorance with a) the extent of known unknowns regarding potential effects of known

693 dependencies and relationships of the target species and possibly affected non-target species and

694 b) not yet determinable effects (unknown unknowns) due to extreme exposure (spread and

695 invasion). The latter may arise from as yet unknown interactions and the inherent instability of

696 genetic information which becomes more relevant with increasing numbers of GDOs and

697 ongoing evolution. Although meanwhile a number of options for limitation of spread and

698 invasion or reversibility of gene drives are brought into the discussion (cp. Table 2) including an

699 initial laboratory-scale trial of a split drive in yeast (DiCarlo et al., 2015b), they still represent

700 theoretical options. A proof of principle in a relevant scale is still lacking and even for the split

701 drive a limitation of its spread in comparison with the equivalent unseparated drive was not yet

702 shown.

703

704 Conclusions

705 Gene drives constitute a tipping point in the technological development of genetic engineering,

706

707

708

709

710

711

712

713

714

715

716

717

718

719

720

721

722

723

724

725

726

727

728

729 due to their inherent capability to spread and invade to either suppress or replace a naturally occurring population. This new functionality separates GDOs from other GMOs released into agricultural ecosystems, so far. Due to the by trend high spatio-temporal range of a released GD, exposure and thereby non-knowledge about possible consequences increases, reaching from enormous scientific uncertainties to vast ignorance.

A gene drive is a technology capable to reproduce itself and potentially undergo mutational changes over time. Not only do gene drives affect the environment, the environment affects the gene drives as well. Thus, a GD engineered in the laboratory, once released will be confronted with evolutionary processes. It is hard to predict how the genetic information of the drive will be influenced by mutation and selection processes post-release. The ecological and evolutionary level of complexity presents a complicated interwoven web of biotic and abiotic factors. The initially small possibility for such effects rises enormously with the depth and intensity of interventions into these systems. A correspondingly extended risk assessment (hazard and exposure assessment) is required to fathom the extent and kind of non-knowledge on the different organizational levels of biosystems that are likely to be affected by gene drives. It is questionable whether our criteria, methods and models for prospective and comparative assessment are already sufficient to adequately investigate exposure potentials of released gene drives. Moreover, for the prospective and comparative assessment of hazards there still exists a lack of adequate criteria, methods and models. Besides the spread of new functionalities, the effects of a strong reduction of populations up to their eradication may evoke complex ecological changes that have to be considered. With regard to risk management, there are no proven management options to mitigate or reverse a once released gene drive. And even if we look at some proposals, just as the drive needs several generations to establish itself, so will the rescue drive. With concrete plans for the release of GDOs, important questions regarding technological,

Peer) reviewing PDF | (2018:11:32627:1:2:NEW 14 Mar 2019) 
730 ecological as well as ethical issues become apparent. There may be great potential benefits but

731 there are also very high reasons for concern.

732 In this work, we presented an overview of different GD techniques which are planned to tackle

733 infectious diseases, invasive species or pest organisms. In order to develop an approach for

734 prospective risk assessment we examined gene drive techniques, comparatively characterizing

735 their range, intensity of intervention, reliability and possible corrective actions. Furthermore,

736 based on their inheritance schemes we presented an assessment of the drive's efficiencies to

737 invade a population that illustrates the high capacity of CRISPR/Cas9-based drives. The analysis

738 revealed a differentiated picture with regard to the potential range of the investigated drives.

739 However, as long as this characterization has to rely on theoretical assumptions or initial

740 experimental results in the laboratory scale, the present assessment should not be used as a basis

741 to choose a "safer" gene drive for release. It rather delivers an early description of the drives

742 specificities that may be a useful contribution for efforts to outline low-risk development paths.

743 There is an urgent demand for further prospective analysis of impact, side effects,

744 countermeasures and the feasibility of low-risk approaches. In some respects, existing risk

745 assessment for pathogenic viruses resembles the criteria of technology characterization. For

746 example the Influenza Risk Assessment Tool (IRAT) (Cox, Trock \& Burke, 2014) of the US-

747 Centers for Disease Control and Prevention (CDC) at least partially apply related criteria for

748 exposure assessment in the categories 'properties of the virus' and 'ecology and epidemiology'

749 (also see on the homepage of the CDC https://www.cdc.gov/flu/pandemic-resources/national-

750 strategy/risk-assessment.htm; last accessed 2019 Feb 06). In the light of the extensive experience

751 with viral infections it should be worth a try to consider the significance of the criteria for viral

752 spread for a further development of the criteria applied in technology assessment of GDs.

753

754

755

756

757

758

759

760

761

762

763

764

765

766

767

768

769

\section{Acknowledgements}

The authors thank Bartholomäus Gruchalski and Dr. Rolf Roth for their help with the mathematical approach for invasiveness.

\section{References}

Ahrens A, Braun A, von Gleich A, Heitmann K, Lißner L. 2005. Hazardous chemicals in products and processes - Substitution as an innovative process. Heidelberg, Germany; New York, USA: Physica Verlag.

Akbari OS, Bellen HJ, Bier E, Bullock SL, Burt A, Church GM, Cook KR, Duchek P, Edwards OR, Esvelt KM, Gantz VM, Golic KG, Gratz SJ, Harrison MM, Hayes KR, James AA, Kaufman TC, Knoblich J, Malik HS, Matthews KA, O’Connor-Giles KM, Parks AL, Perrimon N, Port F, Russell S, Ueda R, Wildonger J. 2015. Safeguarding gene drive experiments in the laboratory. Science 349:927-929. DOI: 10.1126/science.aac7932.

Akbari OS, Chen C-H, Marshall JM, Huang H, Antoshechkin I, Hay BA. 2014. Novel synthetic Medea selfish genetic elements drive population replacement in drosophila, and a 
770

771

772

773

774

775

776

777

778

779

780

781

782

783

784

785

786

787

788

789

790

791

792

793

794

795

796

797

798

799

800

801

802

803

804

805

806

807

808

809

theoretical exploration of Medea-dependent population suppression. ACS Synth Biology 3:015-928.

Akbari OS, Matzen KD, Marshall JM, Huang H, Ward CM, Hay BA. 2013. A synthetic gene drive system for local, reversible modification and suppression of insect populations. Current Biology 23:671-677. DOI: 10.1016/j.cub.2013.02.059.

Alphey L. 2014. Genetic control of mosquitoes. Annu Rev Entomol 59:205-24. DOI: 10.1146/annurev-ento-011613-162002.

Anders G. 1956. Die Antiquiertheit des Menschen: Über die Seelen im Zeitalter der zweiten industriellen Revolution. Munich, Germany.

Australian Academy of Science. 2017. Synthetic gene drives in Australia: implications of emerging technologies.

Beaghton A, Beaghton PJ, Burt A. 2016. Gene drive through a landscape: Reaction-diffusion models of population suppression and elimination by a sex ratio distorter. Theoretical Population Biology 108:51-69. DOI: 10.1016/j.tpb.2015.11.005.

Beeman RW, Friesen KS, Denell RE. 1992. Maternal-effect selfish genes in flour beetles. Science 256:89-92. DOI: 10.1126/science.1566060.

Böschen S, Lenoir D, Scheringer M. 2003. Sustainable chemistry: Starting point and prospects. Naturwissenschaften 90:93-102. DOI: 10.1007/s00114-002-0397-9.

Buchman A, Marshall JM, Ostrovski D, Yang T, Akbari OS. 2018. Synthetically engineered Medea gene drive system in the worldwide crop pest Drosophila suzukii. PNAS 115:4725-4730.

Bull JJ. 2016. Lethal gene drive selects inbreeding. Evolution, Medicine, \& Public Health 1:116. DOI: $10.1093 / \mathrm{emph} /$ eow030.

Burt A. 2003. Site-specific selfish genes as tools for the control and genetic engineering of natural populations. Proc. R. Soc. B 270:921-928. DOI: 10.1098/rspb.2002.2319.

Burt A, Trivers R. 2006. Genes in conflict: The biology of selfish genetic elements. Cambridge MA: Belknap Press/Harvard University Press.

Carareto CMA, Kim W, Wojciechowski MF, O’Grady P, Prokchorova AV, Silva JC, Kidwell

MG. 1997. Testing transposable elements as genetic drive mechanisms using Drosophila P element constructs as a model system. Genetica 101:13-33.

Commision of the European Communities. 2000. Communication from the commission on the precautionary principle. Brussels, Belgium.

Courtier-Orgogozo V, Morizot B, Boëte C. 2017. Agricultural pest control with CRISPR-based gene drive: time for public debate: Should we use gene drive for pest control? EMBO reports:e201744205. DOI: 10.15252/embr.201744205.

Cox NJ, Trock SC, Burke SA. 2014. Pandemic preparedness and the Influenza Risk Assessment Tool (IRAT). Current Topics in Microbiology and Immunology 385:119-136. DOI: $10.1007 / 82 \_2014 \_419$.

Craig GBJ, Hickey WA, VandeHey RC. 1960. An inherited male-producing factor in Aedes aegypti. Science 132:1887-1889. DOI: 10.1126/science.132.3443.1887.

PeerJ reviewing PDF | (2018:11:32627:1:2:NEW 14 Mar 2019) 
810 Curtis CF. 1968. Possible use of translocations to fix desirable genes in insect pest populations. $811 \quad$ Nature 218:368-369.

812 Deredec A, Burt A, Godfray HCJ. 2008. The population genetics of using homing endonuclease 813 genes in vector and pest management. Genetics 179:2013-2026. DOI:

$814 \quad 10.1534 /$ genetics.108.089037.

815 Deutscher Ethikrat (German Ethics Council). 2011. Human-animal mixtures in research $816 \quad$ Opinion. Berlin, Germany: Deutscher Ethikrat.

817 Dhole S, Vella MR, Lloyd AL, Gould F. 2018. Invasion and migration of spatially self- limiting 818 gene drives: A comparative analysis. Evolutionary Applications. 11:794-808. DOI:

$819 \quad$ 10.1111/eva.12583.

820

821

822

823

824

825

DiCarlo JE, Chavez A, Dietz SL, Esvelt KM, Church GM. 2015a. RNA-guided gene drives can efficiently bias inheritance in wild yeast. Nature Biotechnology 33:1250-1255. DOI: $10.1038 /$ nbt.3412.

DiCarlo JE, Chavez A, Dietz SL, Esvelt KM, Church GM. 2015b. Safeguarding CRISPR-Cas9 gene drives in yeast. Nat Biotechnol 33:1250-1255. DOI: 10.1038/nbt.3412.

826

827

828

829

830

831

832

833

834

835

836

837

838

839

840

841

842

843

844

845

846

847

848

Doudna JA, Charpentier E. 2014. The new frontier of genome engineering with CRISPR-Cas9. Science 346. DOI: 10.1126/science.1258096.

Drury DW, Dapper AL, Siniard DJ, Zentner GE, Wade MJ. 2017. CRISPR/Cas9 gene drives in genetically variable and nonrandomly mating wild populations. Science Advances 3:e1601910. DOI: 10.1126/sciadv.1601910.

Eckhoff PA, Wenger EA, Godfray HC, Burt A. 2017. Impact of mosquito gene drive on malaria elimination in a computational model with explicit spatial and temporal dynamics. Proc Natl Acad Sci U S A 114:E255-e264. DOI: 10.1073/pnas.1611064114.

Edgington MP, Alphey L. Population dynamics of engineered underdominance and killer-rescue gene drives in the control of disease vectors. PLOS Computational Biology:1-28. DOI: 10.1371/journal.pcbi.1006059.

Emerson C, James S, Littler K, Filippo R. 2017. Principles for gene drive research. Science 358:1135-1136. DOI: 10.1126/science aap9026.

Engelhard M, Bölker M, Budisa N. 2016. Old and new risks in synthetic biology: Topics and tools for discussion. In: Synthetic Biology Analysed. Ethics of science and technology assessment. Cham, Switzerland: Springer, 51-69.

Esvelt KM, Smidler AL, Catteruccia F, Church GM. 2014. Concerning RNA-guided gene drives for the alteration of wild populations. eLife 3:e03401. DOI: 10.7554/eLife.03401.

European Commission, Scientific Advice Mechanism. 2017. New Techniques in agricultural biotechnology.

European Environment Agency. 2002. Late lessons from early warnings: the precautionary principle 1896-2000. Environmental issue report 22:1-211.

European Parliament Think Tank. 2015. The precautionary principle: Definitions, applications and governance. 
849 Fischer E, Jones J, von Schomberg R. 2006. Implementing the precautionary principle -

850

851

852

853

854

855

856

857

858

859

860

861

862

863

864

865

866

867

868

869

870

871

872

873

874

875

876

877

878

879

880

881

882

883

884

885

886

Perspectives and prospects. Cornwall, Great Britain: MPG Books Ltd, Bodmin.

Fu G, Lees RS, Nimmo D, Aw D, Jin L, Gray P, Berendonk TU, White-Cooper H, Scaife S, Phuc HK, Marinotti O, Jasinskiene N, James AA, Alphey L. 2010. Female-specific flightless phenotype for mosquito control. PNAS 107:4550-4554. DOI: $10.1073 /$ pnas. 1000251107.

Galizi R, Doyle LA, Menichelli M, Bernardini F, Deredec A, Burt A, Windbichler N, Crisanti A. 2014. A synthetic sex ratio distortion system for the control of the human Malaria mosquito. Nature Communications 5:3977. DOI: 1038/ncomms4977.

Gantz VM, Bier E. 2015. Genome editing. The mutagenic chain reaction: a method for converting heterozygous to homozygous mutations. Science 348:442-4. DOI: 10.1126/science.aaa5945.

Gantz VM, Jasinskiene N, Tatarenkova O, Fazekas A, Macias VM, Bier E, James AA. 2015. Highly efficient Cas9-mediated gene drive for population modification of the malaria vector mosquito Anopheles stephensi. Proceedings of the National Academy of Sciences 112:E6736-E6743. DOI: 10.1073/pnas.1521077112.

Giese B, von Gleich A. 2015. Hazards, risks, and low hazard development paths of synthetic biology. In Giese B, Pade C, Wigger H, Gleich A von. Synthetic biology - Character and impact. Heidelberg: Springer International Publishing.

von Gleich A. 1989. Der wissenschaftliche Umgang mit der Natur: über die Vielfalt harter und sanfter Naturwissenschaften. Campus Verlag.

Gokhale CS, Reeves RG, Reed FA. 2014. Dynamics of a Combined Medea-Underdominant Population Transformation System. BMC Evolutionary Biology 14:1-9. DOI: 10.1186/1471-2148-14-98.

Gould F, Huang Y, Legros M, Lloyd AL. 2008. A Killer-Rescue system for self-limiting gene drive of anti-pathogen constructs. Proceedings of the Royal Society B: Biological Sciences 275:2823-2829. DOI: 10.1098/rspb.2008.0846.

Grunwald A. 2016. Synthetic biology: Seeking for orientation in the absence of valid prospective knowledge and of common values. In: The argumentative turn in Policy analysis. Cham, Switzerland: Springer, 325-344.

Hastings IM. 1994. Selfish DNA as a method of pest control. Philosophical Transactions of the Royal Society B 344:313-324.

Helleu Q, Gérard PR, Montchamp-Moreu C. 2015. Sex chromosome drive. Cold Spring Harbor Perspectives in Biology 7:a017616. DOI: 10.1101/cshperspect.a017616.

Hochkirch A, Beninde J, Fischer M, Krahner A, Lindemann C, Matenaar D, Rohde K, Wagner N, Wesch C, Wirtz S, Zink A, Lötters S, Schmitt T, Proelss A, Veith M. 2017. License to kill? - Disease eradication programs may not be in line with the convention on biological diversity. Conservation Letter 11:1-6. DOI: 10.1111/conl.12370.

Peer) reviewing PDF | (2018:11:32627:1:2:NEW 14 Mar 2019) 
887 Huang Y, Magori K, Lloyd AL, Fred Gould. 2007. Introducing transgenes into insect

888

889

890

891

892

893

894

895

896

897

898

899

900

901

902

903

904

905

906

907

908

909

910

911

912

913

914

915

916

917

918

919

920

921

922

923

924

925 populations using combined dene-drive strategies: modeling and analysis. Insect Biochem Mol Biol 37:1054-1063. DOI: 10.1016/j.ibmb.2007.06.002.

Jinek M, Chylinski K, Fonfara I, Hauer M, Doudna JA, Charpentier E. 2012. A programmable dual-RNA-guided DNA endonuclease in adaptive bacterial immunity. Science 337:81621. DOI: $10.1126 /$ science. 1225829.

Jonas H. 1979. Das Prinzip Verantwortung: Versuch einer Ethik für die technologische Zivilisation. Francfort/Main, Germany: Suhrkamp.

Jonas H. 1985. Technik, Medizin und Ethik. Francfort/Main, Germany: Suhrkamp.

KaramiNejadRanjibar M, Eckermann KN, Ahmed HMM, Sánchez C. HM, Dippel S, Marshall JM, Wimmer EA. 2018. Consequences of resistance evolution in a Cas9-based sex conversion-suppression gene drive for insect pest management. PNAS 115:6189-6194. DOI: $10.1073 /$ pnas.1713825115.

Kyrou K, Hammond AM, Galizi R, Kranjc N, Burt A, Beaghton A, Nolan T, Crisanti A. 2018. A CRIS PR-Cas 9 gene drive targeting doublesex causes complete population suppression in caged Anopheles gambiae mosquitoes. Nature Biotechnology. DOI: 10.1038/nbt.4245.

Lambert B, North A, Burt A, Godfray HCJ. 2018. The use of driving endonuclease genes to suppress mosquito vectors of malaria in temporally variable environments. Malaria Journal 17:1-14. DOI: 10.1186/s12936-018-2259-8.

Larracuente AM, Presgraves DC. 2012. The selfish segregation distorter gene complex of Drosophila melanogaster. Genetics 192:33-53. DOI: 10.1534/genetics.112.141390.

Ledford H. 2015. CRISPR, the disruptor. Nature 522:20-24. DOI: 10.1038/522020a.

Li Z, Liu Z-B, Xing A, Moon BP, Koellhoffer JP, Huang L, Ward TR, Clifton E, Falco SC, Cigan AM. 2016. Cas9-guide RNA directed genome editing in soybean. Plant Physiology 169:960-970. DOI: 10.1104/pp.15.00783.

Lindholm AK, Dyer KA, Firman RC, Fishman L, Forstmeier W, Holman L, Johannesson H, Knief U, Kokko H, Larracuente AM, Manser A, Montchamp-Moreau C, Petrosyan VG, Pomiankowski A, Presgraves DC, Safronova LD, Sutter A, Unckless RL, Verspoor RL, Wedell N, Wilkinson GS, Price TAR. 2016. The ecology and evolutionary dynamics of meiotic drive. Trends in Ecology \& Evolution 31:315-326. DOI: 10.1016/j.tree.2016.02.001.

Linkov I, Trump BD, Anklam E, Berube D, Boisseasu P, Cummings C, Ferson S, Florin M-V, Goldstein B, Hristozov D, Jensen KA, Katalagarianakis G, Kuzma J, Lambert JH, Malloy T, Malsch I, Marcomini A, Merad M, Palma-Oliveira J, Perkins E, Renn O, Seager T, Stone V, Vallero D, Vermeire T. 2018. Comparative, collaborative, and integrative risk governance for emerging technologies. Environment Systems and Decisions 38:170-176.

Lin CC, Potter CJ. 2016. Non-Mendelian dominant maternal effects caused by CRISPR/Cas9 transgenic components in Drosophila melanogaster. G3 Genes, Genomes, Genetics 6:3685-3691. DOI: 10.1534/g3.116.034884. 
926 Marshall JM, Akbari OS. 2017. Can CRISPR-based gene drive be confined in the wild? A

927

928

929

930

931

932

933

934

935

936

937

938

939

940

941

942

943

944

945

946

947

948

949

950

951

952

953

954

955

956

957

958

959

960

961

962

963

964 question for molecular and population biology. bioRxiv:1-16. DOI: 10.1101/173914.

Marshall JM, Buchman A, Sánchez C. HM, Akbari OS. 2017. Overcoming evolved resistance to population-suppressing homing-based gene drives. Nature Scientific Reports 7:1-12. DOI: $10.1038 / \mathrm{s} 41598-017-02744-7$.

National Academies of Sciences. 2016. Gene Drives on the Horizon: Advancing Science, Navigating Uncertainty, and Aligning Research with Public Values. Washington, DC: The National Academies Press.

Newton ME, Wood RJ, Southern DI. 1976. A Cytogenetic Analysis of Meiotic Drive in the Mosquito, Aedes Aegypti (L.). Genetica 46:297-318.

Noble C, Adlam B, Church GM, Esvelt KM, Nowak MA. 2018. Current CRISPR gene drive systems are likely to be highly invasive in wild populations. eLife 7:e33423. DOI: 10.7554/eLife.33423.

Noble C, Min J, Olejarz J, Buchthal J, Chavez A, Smidler AL, DeBenedictis EA, Church GM, Nowak MA, Esvelt KM. 2016. Daisy-chain gene drives for the alteration of local populations. bioRxiv:057307.

Noble C, Olejarz J, Esvelt KM, Church GM, Nowak MA. 2017. Evolutionary dynamics of CRISPR gene drives. Science Advances 3:e1601964. DOI: 10.1126/sciadv.1601964.

Owen R, Crane M, Grieger K, Handy R, Linkov I, Depledge M. 2009. Strategic Approaches for the Management of Environmental Risk Uncertainties Posed by Nanomaterials Nanomaterials: Risks and Benefits. Dordrecht, Netherlands: Springer.

Peters LL, Barker JE. 1993. Novel inheritance of the murine severe combined anemia and thrombocytopenia (scat) phenotype. Cell 74:135-142. DOI: 10.1016/00928674(93)90301-6.

Ping G. 2017. Invasive species management on military lands: Clustered regularly interspaced short palindromic repeat/CRISPR-associated protein 9 (CRISPR/Cas9)-based gene drives. U.S. Army Engineer Research and Development Center (ERDC) Environmental Laboratory.

Reeves RG, Bryk J, Altrock PM, Denton JA, Reed FA. 2014. First Steps towards Underdominant Genetic Transformation of Insect Populations. PLOS ONE 9:e97557 1-9. DOI: 10.1371/journal.pone.0097557.

Regalado A. 2017. Farmers seek to deploy powerful gene drive. MIT Technology Review.

Rip A. 2006. 13. The tension between fiction and precaution in nanotechnology. In: Implementing the precautionary principle: Perspectives and prospects. Cornwall, Great Britain: MPG Books Ltd, Bodmin, 270 pp.

Serebrovskii AS. 1940. On the possibility of a new method for the control of insect pests. Zool. Zhurnal 19:618-630.

Silver LM. 1993. The peculiar journey of a selfish chromosome: mouse t-haplotypes and meiotic drive. Trends in Genetics 9:250-254. DOI: 10.1016/0168-9525(93)90090-5. 
965 Simon S, Otto M, Engelhard M. 2018. Synthetic gene drive: between continuity and novelty. $966 \quad$ EMBO Reports:e45760.

967 Sinkins SP, Gould F. 2006. Gene drive systems for insect disease vectors. Nature Reviews

$968 \quad$ Genetics 7:427-435. DOI: 10.1038/nrg1870.

969 Steinfeldt M, von Gleich A, Petschow U, Haum R. 2007. Nanotechnologies, Hazards and

$970 \quad$ Resource Efficiency. Heidelberg, Germany: Springer.

971 Sweeny TL, Barr AR. 1978. Sex ratio distortion caused by meiotic drive in a mosquito, Culex

972 pipiens L. Genetics 88:427-446.

973 Tanaka H, Stone HA, Nelson DR. 2017. Spatial gene drives and pushed genetic waves.

$974 \quad$ Proceedings of the National Academy of Sciences 114:8452-8457. DOI:

$975 \quad 10.1073 /$ pnas.1705868114.

976 Taylor DR. 1994. The genetic basis of sex ratio in Silene alba (= S. latifolia). Genetics 136:641$977 \quad 651$.

978 The Rio declaration on environment and development. 1992.

979 Unckless RL, Clark AG, Messer PW. 2016. Evolution of resistance against CRISPR/Cas9 gene

980 drive. Genetics:genetics.116.197285. DOI: 10.1534/genetics.116.197285.

981 Unckless RL, Messer PW, Connallon T, Clark AG. 2015. Modeling the Manipulation of Natural

982 Populations by the Mutagenic Chain Reaction. Genetics 201:425-31. DOI:

$983 \quad 10.1534 /$ genetics.115.177592.

984 United Nations. 2000. Cartagena Protocol on Biosafety to the Convention on Biological

985 Diversity. Montréal, Canada: Secretariat of the Convention on Biological Diversity.

986 Ward CM, Su JT, Huang Y, Lloyd AL, Gould F, Hay BA. 2011. Medea selfish genetic elements

987 as tools for altering traits of wild populations: a theoretical analysis. Evolution 65:1149-

988 1162. DOI: $10.1111 / \mathrm{j} .1558-5646.2010 .01186 . x$.

989 Webber BL, Raghu S, Edwards OR. 2015. Opinion: Is CRISPR-based gene drive a biocontrol

990 silver bullet or global conservation threat? Proc Natl Acad Sci U S A 112:10565-7. DOI:

$991 \quad 10.1073 /$ pnas.1514258112.

992 Weichenhan D, Traut W, Kunze B, Winking H. 1996. Distortion of Mendelian recovery ratio for

993 a mouse HSR is caused by maternal and zygotic effects. Genetical Research 68:125-129.

994 DOI: $10.1017 /$ S0016672300034017.

995 


\section{Figure 1}

Criteria of prospective technology characterization with corresponding gene drivespecific effects and options.

Technological power is not in the focus of this rather general prospective study due to the very early innovation phase, where the particular design (esp. their cargo) and application context of gene drives is not yet clear.

\section{Depth of Intervention}

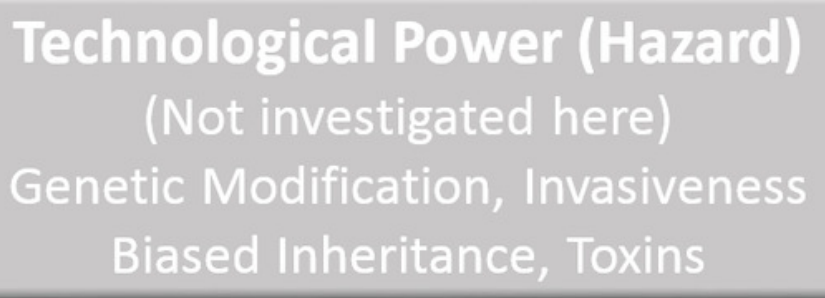

\section{Technological Range (Exposure)}

Non-Mendelian Inheritance, altered Fitness, Self-Limiting/Self-Sustaining

\section{Intensity of Intervention}

\section{Mass}

Size of necessary Releases

\section{Frequency}

Number of necessary Releases

\section{Reliability}

On-, Off-, Non-Target Effects, Resistance-Formation, Mutation, LinkageLoss of Cargo and Driver, Coevolution of Pathogen

\section{Corrigibility}

Proposed Options: Second Generation Drive, Overwriting Drive 


\section{Figure 2}

Mechanism of CRISPR/Cas9-based gene drives.

A gene drive organism carries the gene drive cassette and mates with a wild type. The gene drive cassette expresses the CRISPR/Cas9 complex, which then cuts its recognition site defined by the gRNA on the homologous chromosome. This cut can then either be repaired by homology directed repair (HDR) copying the gene drive cassette into the cut region or by mechanisms creating a homing resistant allele, like Non-Homologous End Joining (NHEJ) or Microhomology-Mediated End Joining (MMEJ), (adapted from Esvelt et al., 2014) . 

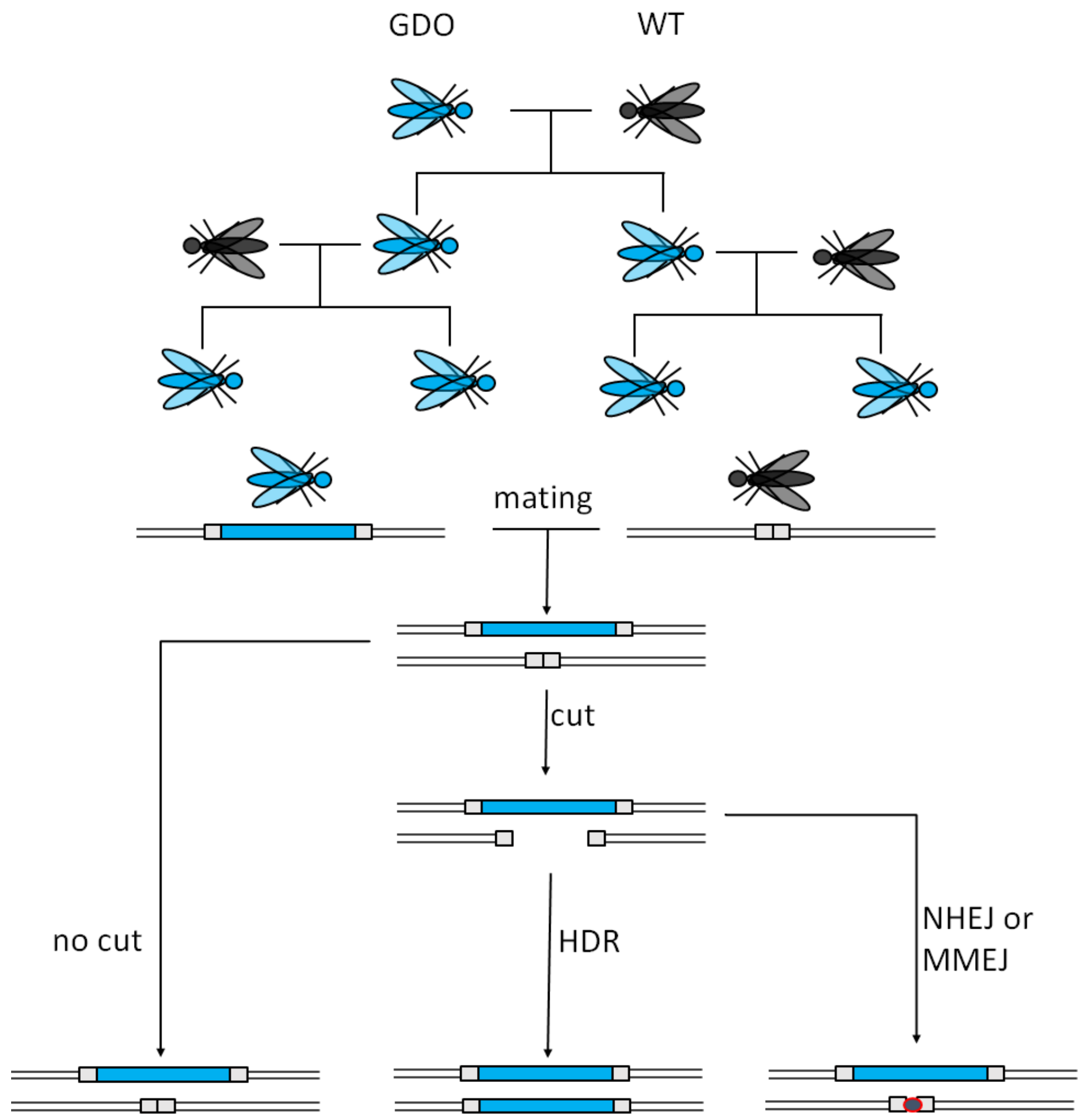


\section{Figure 3}

Cross section overlays of the negative controls for the model represented on the fSRIDL technique and the fate of a transgene either conferring a fitness loss or gain.

Red $=$ Wild type population percentage below $5 \%$; Blue $=$ Wild type population percentage above $95 \%$. Black numbers and lines represent the respective generation post-release. Lines were inserted by hand for clarity.
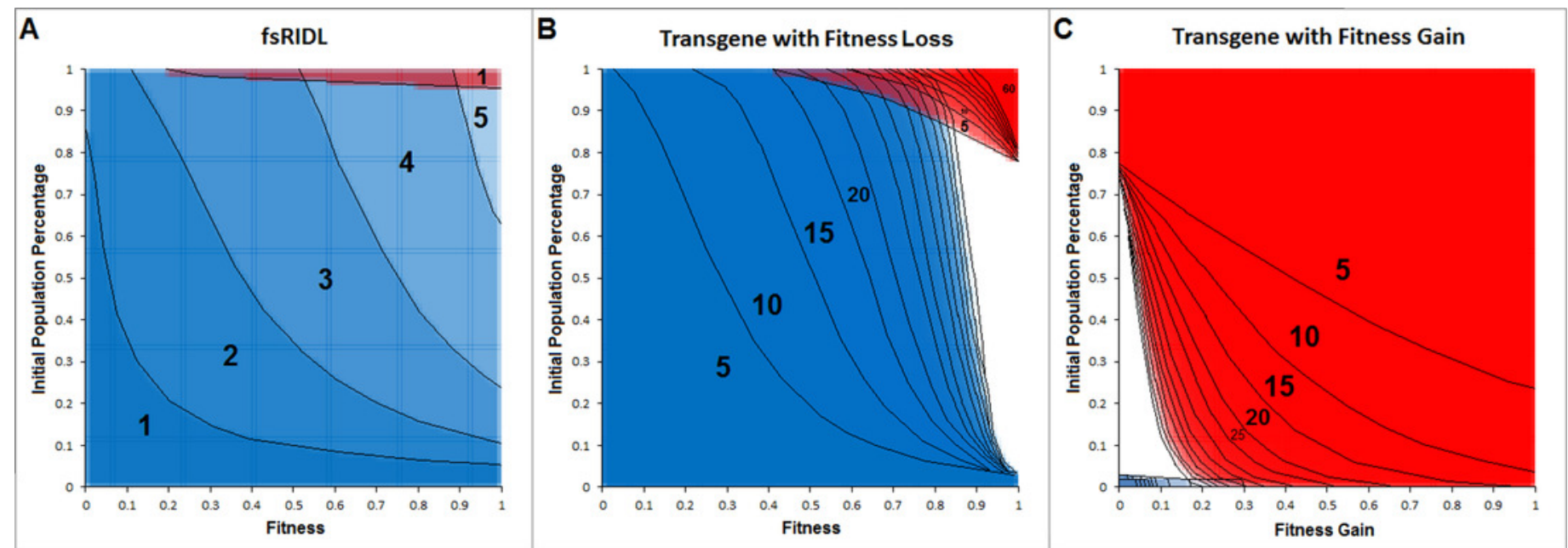


\section{Figure 4}

Cross section overlays of fitness and initial release population percentage for different gene drive techniques.

Red $=$ Wild type population percentage below $5 \%$; Blue $=$ Wild type population percentage above $95 \%$. Green = Population homozygous for resistance alleles above 95\%. Black numbers and lines represent the respective generation post-release. Black lines were inserted by hand for clarity.
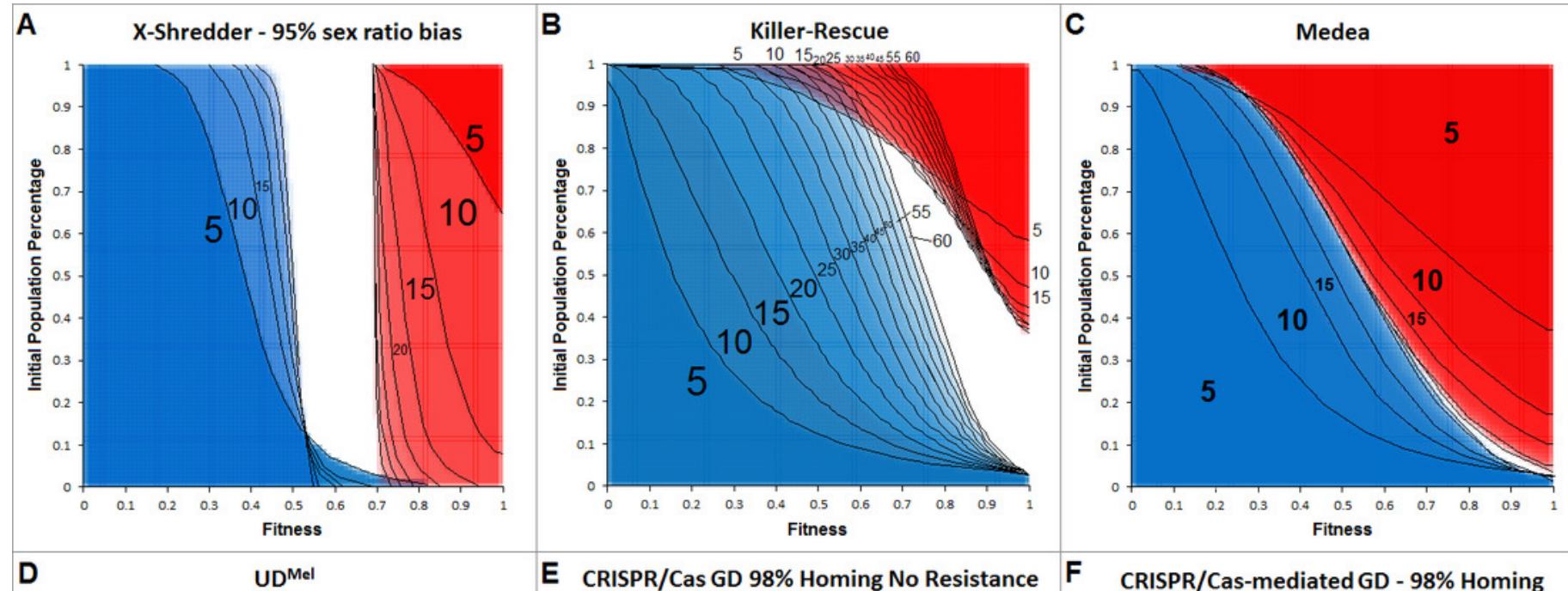

D

E CRISPR/Cas GD 98\% Homing No Resistance
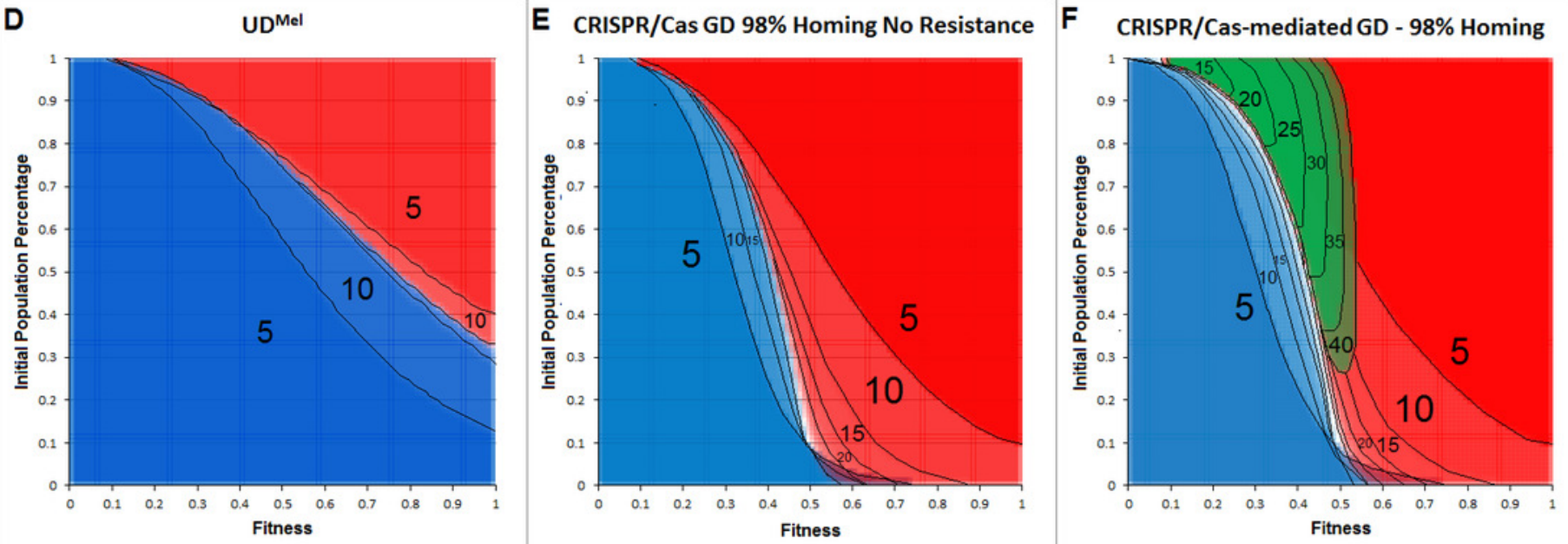


\section{Figure 5}

Invasiveness as ratio of complete population replacement vs. loss of gene drive construct per generation.

Each gene drive technique shows an asymptotic behaviour with the exception of the CRISPR/Cas-mediated gene drives, due to the formation of resistance alleles (labelled as w/ Res). A comparable CRISPR/Casmediated gene drive without resistance allele formation (labelled as w/o Res) shows asymptotic behaviour as well.

A: GD techniques on a decimal scale.

B: GD Techniques on a logarithmic scale compared to the fitted curves for transgenes with fitness loss (power) and fitness gain (polynomial). 
A

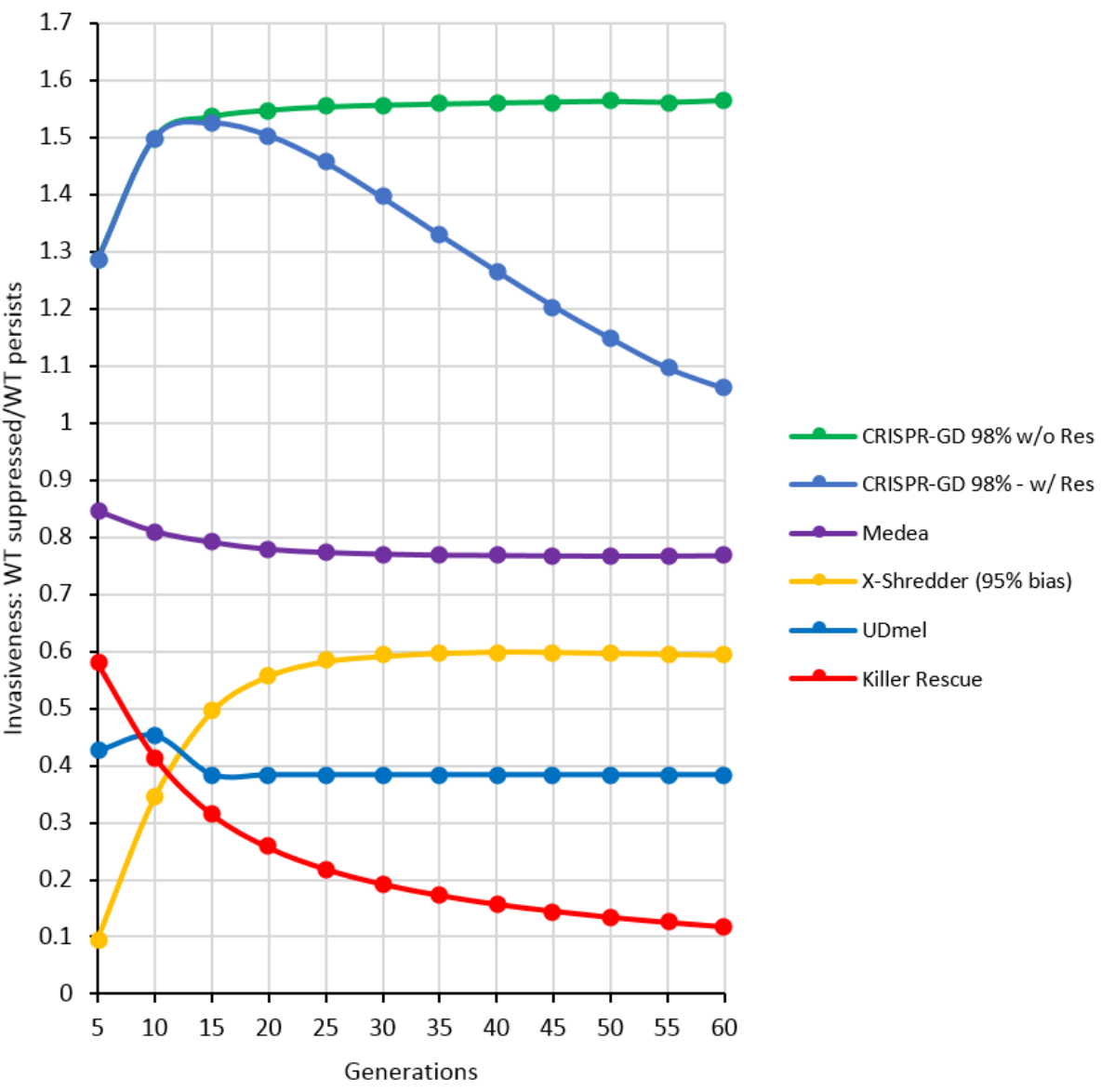

B

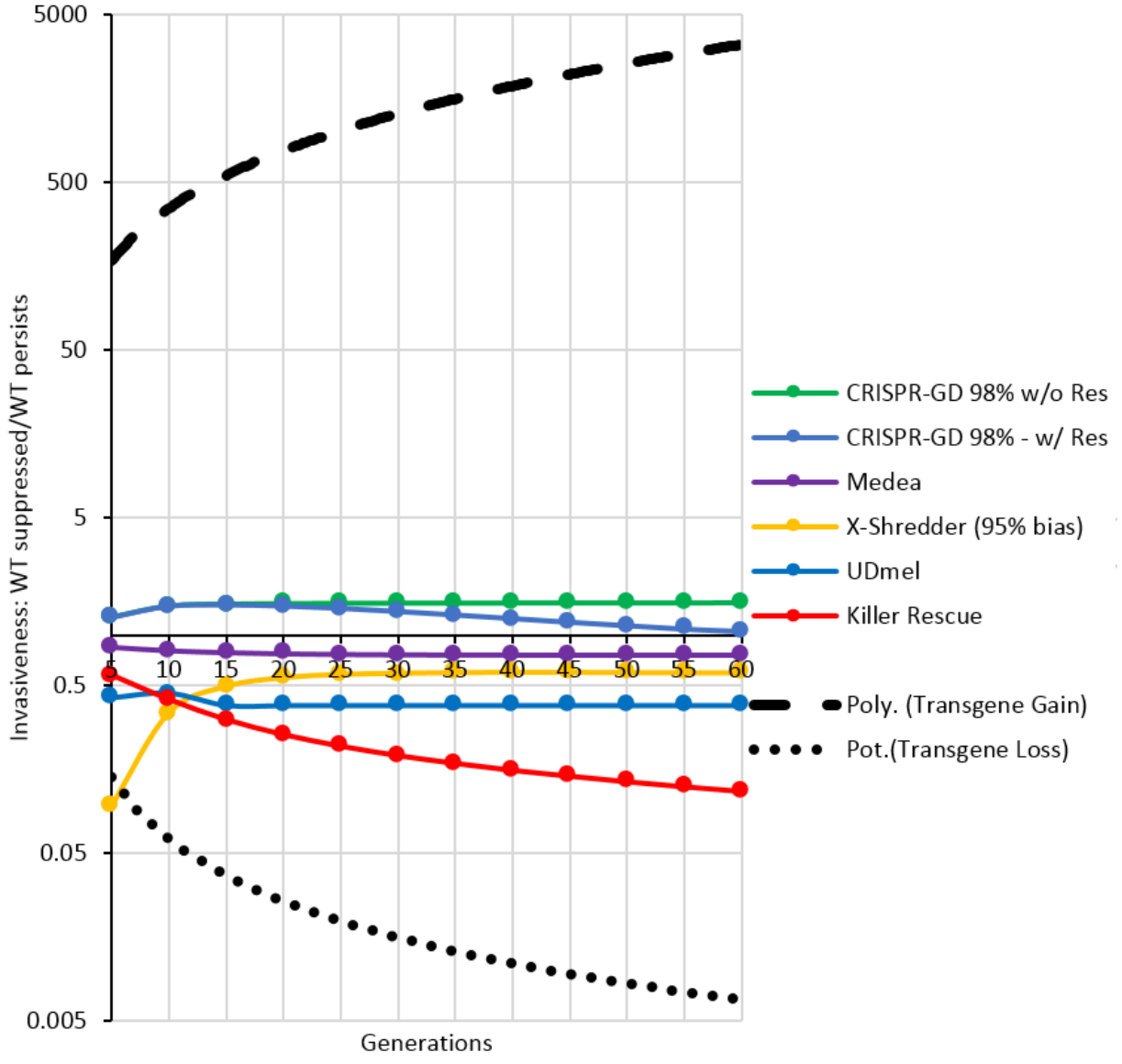

Peer] reviewing PDF | (2018:11:32627:1:2:NEW 14 Mar 2019) 


\section{Table $\mathbf{1}$ (on next page)}

Ranking of gene drive invasiveness 
1

\begin{tabular}{|c|c|c|}
\hline Gene drive technology & Asymptote threshold & Invasiveness \\
\hline CRISPR/Cas & 1.5644 & $100 \%$ \\
\hline (without resistance formation) & & \\
\hline Medea & 0.7682 & $49,1 \%$ \\
\hline Y-linked X-Shredder (95\% sex bias) & 0.5941 & $29,7 \%$ \\
\hline Two-Locus Underdominance & 0.4354 & $27,8 \%$ \\
\hline Killer-Rescue & 0.1118 & $7,1 \%$ \\
\hline
\end{tabular}

2 
Table 2 (on next page)

Comparison of gene drive-specific characteristics 
1 Table 2: Comparison of gene drive-specific characteristics

\begin{tabular}{|c|c|c|c|c|c|c|}
\hline & & X-Shredder & Killer-Rescue & Medea & Two-locus UD & CRISPR/Cas \\
\hline & $\begin{array}{l}\text { Mode of } \\
\text { action }\end{array}$ & $\begin{array}{c}\text { Sex ratio/ } \\
\text { Chromosomal } \\
\text { disruption }\end{array}$ & $\begin{array}{l}\text { Toxin/ } \\
\text { Antidote }\end{array}$ & $\begin{array}{l}\text { Toxin/ } \\
\text { Antidote }\end{array}$ & $\begin{array}{l}\text { Toxin/ } \\
\text { Antidote }\end{array}$ & $\begin{array}{l}\text { Heterozygote to } \\
\text { homozygote } \\
\text { conversion }\end{array}$ \\
\hline \multirow{3}{*}{$\begin{array}{c}\text { Depth of } \\
\text { intervention }\end{array}$} & (Power) Class & Suppression & Replacement & Replacement & Replacement & Replacement \\
\hline & Range & High & Low & High & Low & High \\
\hline & Invasiveness & Moderate & Low & High & Moderate & Very high \\
\hline $\begin{array}{l}\text { Intensity of } \\
\text { intervention }\end{array}$ & & High & High & High & High & Low \\
\hline \multirow[t]{2}{*}{ Reliability } & $\begin{array}{l}\text { Resistance } \\
\text { formation }\end{array}$ & Very unlikely & Possible & Possible & Unlikely & Likely \\
\hline & Linkage Loss & unknown & unknown & unlikely & Unlikely & Likely \\
\hline $\begin{array}{c}\text { Risk } \\
\text { management }\end{array}$ & & $\begin{array}{c}\text { None, maybe } \\
\text { CRISPR/Cas- } \\
\text { based overwriting } \\
\text { drive }\end{array}$ & $\begin{array}{l}\text { Wild type } \\
\text { release }\end{array}$ & $\begin{array}{l}2^{\text {nd }} \text { generation } \\
\text { Medea drive }\end{array}$ & Wild type release & $\begin{array}{l}\text { Overwriting } \\
\text { drive }\end{array}$ \\
\hline
\end{tabular}

2 